\title{
Explicit Detection of the Mechanism of Platinum Nanoparticle Shape Control by Polyvinylpyrrolidone
}

\author{
Jin-Yu Ye, ${ }^{\dagger,}$ Gary A. Attard, ${ }^{*},{ }^{\ddagger}$ Ashley Brew, ${ }^{\ddagger}$ Zhi-You Zhou, ${ }^{\dagger}$ Shi-Gang Sun, ${ }^{*}{ }^{\dagger}$ David J. Morgan, ${ }^{\ddagger}$ \\ and David J. Willock \\ ${ }^{\dagger}$ State Key Laboratory of Physical Chemistry of Solid Surfaces, Department of Chemistry, College of Chemistry and Chemical \\ Engineering, Xiamen University, Xiamen, 361005, China \\ ${ }^{\ddagger}$ Cardiff Catalysis Institute, School of Chemistry, Cardiff University, Park Place, Cardiff, CF10 3AT, U.K.
}

\section{Supporting Information}

ABSTRACT: The irreversible adsorption of polyvinylpyrrolidone (PVP) on a series of well-defined platinum single crystal electrode surfaces has been investigated using voltammetry, ex situ XPS and DFT calculations. It is found that the adsorption of PVP is highly structure sensitive with strong adsorption exhibited by step and $\{100\}$ terrace sites with only weak interactions observed between PVP and $\operatorname{Pt}\{111\}$ terraces, at least at low PVP surface concentrations. Subsequent investigations using $\mathrm{CO}$ electrooxidation confirmed that blocking of platinum surface sites by PVP toward CO chemisorption was marked for $\operatorname{Pt}\{100\}$ terraces but hardly occurred at all at $\operatorname{Pt}\{111\}$ terraces. Density Functional Theory calculations also confirmed that the monomer of PVP interacts more strongly with $\mathrm{Pt}\{100\}$ compared to $\mathrm{Pt}\{111\}$ sites (-142 and $-125 \mathrm{~kJ} \mathrm{~mol}^{-1}$

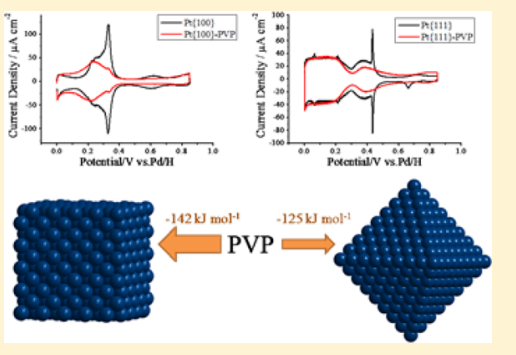
respectively). Ex situ XPS studies suggested that the main PVP-Pt interaction is associated with charge transfer from the carbonyl substituent of PVP toward the metal surface in accordance with earlier studies of PVP adsorbed on polycrystalline platinum surfaces. Irreversible adsorption of $\mathrm{Pt}$ adatoms onto $\mathrm{Pt}\{h k l\}$ surfaces with and without PVP-surface modification demonstrated a marked preference for $\{100\}$ facet formation on $\operatorname{Pt}\{100\}$ surfaces but no corresponding preferential $\{111\}$ facet growth on Pt $\{111\}$ when PVP was present. Hence, the shape control exhibited by PVP in expediting the formation of cubic Pt nanoparticles is explicitly confirmed as arising from relatively weak PVP chemisorption on Pt $\{111\}$ facets at low PVP surface loading.

\section{INTRODUCTION}

Nanoparticles of a specific shape may be created via colloidal methods of metal salt reduction in the presence of capping agents. The mechanism by which such structure directing agents (SDAs) are believed to operate involves preferential deposition onto one crystallographic plane relative to others. ${ }^{1-4}$ This phenomenon arises because the surface energy of the plane at which the SDA is adsorbed is lowered so that further metal deposition is inhibited relative to the other, available planes. In order to gain greater control over NP shape, further understanding of the role that an SDA plays in particle growth is needed. In what follows, we utilize cyclic voltammetry in particular to locate explicitly and precisely the adsorption sites favored by one such structure directing agent, polyvinylpyrrolidone (PVP). This polymer is thought to interact strongly with the $\{100\}$ plane of many face centered cubic metals such as copper, platinum, palladium, gold, and silver. ${ }^{5}$

In gaining an understanding of the interaction of PVP with metal NPs, spectroscopic techniques such as FTIR, ${ }^{6,7} \mathrm{XPS}^{8}$ and UV-Raman ${ }^{6,7}$ have been utilized. UV-Raman and FTIR results indicate that PVP adsorbs onto Pt via the lone pair of electrons on the oxygen atom, as signified by a decrease in the $\mathrm{C}=\mathrm{O}$ stretching frequency of the pyrrolidone ring. ${ }^{6}$ The rhodiumPVP interaction was investigated by UV-Raman and it was found to be stronger than for platinum but of the same nature; i.e., binding of PVP was occurring via oxygen-metal bond formation. ${ }^{7}$ XPS studies provided support for a model in which the mode of bonding of PVP with Pt was facilitated via the carbonyl group. ${ }^{8}$ This study also showed that the direction of the charge transfer of the carbonyl-platinum bond was dependent on the size of the NP. $\mathrm{C}=\mathrm{O} \rightarrow$ Pt charge transfer was seen at small nanoparticle sizes ( $7 \mathrm{~nm}$ or less) and $\mathrm{C}=\mathrm{O}$ $\leftarrow$ Pt at larger sizes $(>25 \mathrm{~nm}){ }^{8}$ A difference in PVP binding with particle size has also been reported for Pd NPs. ${ }^{9}$ Fine nanoparticles ( $\sim 6.7 \mathrm{~nm}$ and smaller) formed from solutions containing relatively large PVP:Pd molar ratios were found to adsorb PVP via the carbonyl group only. The nitrogen of the pyrrolidone ring was seen to be increasingly involved in binding at larger particle sizes so that for Pd particles larger than $8.4 \mathrm{~nm}$ (synthesized using lower PVP:Pd mole ratios), a bridge binding mode was observed which involved both oxygen and nitrogen atoms. It was suggested in this work that these large particles may lead to breaking of the carbon-nitrogen bond of the adsorbing PVP molecule. ${ }^{9}$ The product of this dissociative reaction would then be adsorbed on Pd NPs with separated oxygen (carboxylate) and nitrogen ligands.

Received: November 6, 2015

Revised: $\quad$ March 23, 2016

Published: March 23, 2016 
Progress toward understanding differences in PVP-metal binding has been published recently by Fichthorn et al., ${ }^{10,11}$ who examined the interaction of PVP with $\operatorname{Ag}\{100\}$ and $\mathrm{Ag}\{111\}$ surfaces using theoretical methods capable of delineating the various bonding contributions associated with PVP-Ag binding. They showed that the interaction between a single 2-pyrrolidone monomer and the $\operatorname{Ag}\{100\}$ face is only slightly stronger than its interaction with the $\operatorname{Ag}\{111\}$ plane. This difference increases exponentially however with polymer chain length so that, at 9 monomer units of PVP, binding on $\operatorname{Ag}\{100\}$ is $\sim 10^{8}$ times greater than for $\operatorname{Ag}\{111\}$. The origin for this difference was attributed to the stronger overlap of the 2pyrrolidone p-orbitals with the $\operatorname{Ag}\{100\}$ surface d-band structure. $^{11}$ A recent FTIR-electrochemical study of partially PVP covered Pt nanoparticles points to a promotional effect of PVP in the methanol electrooxidation reaction, the extent of which depended on the overall morphology of the $\mathrm{Pt}$ nanoparticles. $^{12}$ We too have reported that the enhanced selectivity toward alkyne to alkene hydrogenation on PVPmodified Pt could be interpreted as being due to preferential adsorption of PVP at defect sites. ${ }^{13}$ We shall expound on this idea in the present study.

Gasparatto et al. examined the adsorption of PVP electrochemically on platinum single crystal electrode surfaces using cyclic voltammetry. ${ }^{14}$ They found that Pt electrooxidises PVP, and moreover, it is the products of this electrooxidation that adsorb on the surface of Pt. Electrooxidation occurred to similar degrees on both $\mathrm{Pt}\{100\}$ and $\{111\}$ surfaces although significant structure sensitivity on platinum was indicated as signified by different CV profiles for $\{111\},\{100\}$, and $\{110\}$ electrode surfaces. In addition, these workers both confirmed the irreversible blocking of Pt surface sites by PVP and also a narrow range of potential in which PVP was stable.

As mentioned earlier, a mechanism to explain how PVP controls NP growth must consider how the polymer interacts differently with the various basal planes. To our knowledge, besides the study by Gasparatto et al. ${ }^{14}$ there has been no experimental study which demonstrates how PVP interacts with $\{111\}$ surfaces in a distinctly different manner to $\{100\}$ surfaces in terms of experimentally comparing the relative magnitude of the Pt-PVP interaction at the level of local surface sites. More usually, such deductions have been made post hoc by consideration of the actual outcome of an SDA process (when a nanoparticle has already formed). Xiaet al. ${ }^{15}$ found, using Raman spectroscopy, that there appeared to be a much greater intensity of the PVP carbonyl stretch from nanocubes compared to octahedral silver nanoparticles. This they ascribed to a greater surface coverage of PVP on $\{100\}$ planes than $\{111\}$ planes, hence facilitating the expected SDA performance of PVP.

The results presented in the present study regarding the role of PVP in the structure directing effect of nanoparticles by the use of $\mathrm{Pt}\{\mathrm{hkl}\}$ single crystal surfaces in particular, highlight specific structure sensitive features of PVP under well-defined conditions. For the first time, explicit detection of PVP adsorbing at particular surface sites including steps is reported. Moreover, a model concerning the switch from PVP-induced cubic to tetrahedral/octahedral nanoparticle growth at increasing surface coverages of PVP on Pt surfaces is proposed based on changes in the extent of site selectivity by PVP at highest PVP loadings.

\section{EXPERIMENTAL SECTION}

Preparation of Well-Defined Electrodes and Electrochemical Apparatus. Pt $\{h k l\}$ single crystals were prepared using the Clavillier method. ${ }^{16}$ Before electrochemical characterization, the platinum single crystals were flame annealed in a Bunsen burner and cooled in hydrogen. ${ }^{17}$ After the electrodes had cooled to ambient temperature, a droplet of ultrapure water was attached to the crystal face and the electrode was transferred to an electrochemical cell in order to perform cyclic voltammetry measurements as described previously. ${ }^{18} \mathrm{~A}$ platinum mesh counter electrode was employed together with a palladium hydride reference electrode (prepared by bubbling hydrogen over a palladium wire for half an hour to form a stable palladium beta-hydride phase). A CHI 800 potentiostat interfaced with a PC using proprietary software was employed to collect all cyclic voltammetry $(\mathrm{CV})$ data. The resulting CVs $\mathrm{Pt}\{h k l\}$ of all surfaces were found to be consistent with previously reported clean, well ordered standard profiles.

Chemicals and Materials. Aqueous electrolyte solutions (0.1 mol dm ${ }^{-3} \mathrm{HClO}_{4}$ and $\mathrm{H}_{2} \mathrm{SO}_{4}$ ) were all prepared using high purity reagents (Perchloric acid 70\% Suprapur, 96\% sulfuric acid Suprapur supplied by Merck) dissolved in ultrapure Milli-Q water $(18.2 \mathrm{M} \Omega \cdot \mathrm{cm})$ and degassed with high purity nitrogen in order to remove dissolved oxygen and carbon dioxide. For $\mathrm{CO}$ dosing, a gas bubbler containing ultrapure water through which gaseous CO (Air liquide, N48) was passed replaced the standard hydrogen cooling method referred to above and a droplet of the $\mathrm{CO}$ saturated water was used instead to protect the crystal surface upon transfer to the electrochemical cell. After a meniscus contact was formed under potential control $(0.05 \mathrm{~V}$ vs $\mathrm{Pd} / \mathrm{H}$ reference $)$, a short period of $2 \mathrm{~min}$ allowed for excess dissolved $\mathrm{CO}$ to disperse. A potential sweep to $0.85 \mathrm{~V}$ was then used to observe $\mathrm{CO}$ electrooxidation. PVP (10000 amu molecular weight) was irreversibly adsorbed onto the Pt single crystals by dipping the freshly flame annealed electrode into a $10^{-4} \mathrm{~mol} \mathrm{dm}{ }^{-3}$ solution for various times ranging from 1 to $10 \mathrm{~s}$. The electrodes were then rinsed with ultrapure water before being transferred to a clean, polymer free cell for $\mathrm{CV}$ analysis. Oxygen reduction reaction (ORR) measurements were carried out using a hanging meniscus configuration and the experimental apparatus and analytical protocols have been described elsewhere. ${ }^{19}$ Irreversible adsorption of $\mathrm{Pt}$ onto clean and PVP-modified single crystal electrodes was expedited using a $2 \times 10^{-4} \mathrm{M}$ aqueous solution of chloroplatinic acid via forced deposition protocols described previously for palladium deposition on platinum. ${ }^{20}$ Deposition was carried out for a fixed time period by exposing a droplet of the aqueous chloroplatinic acid (attached to the Clavilier bead electrode) to a stream of hydrogen gas. After being rinsed with ultrapure water, the electrode would be returned to the electrochemical cell for voltammetric characterization. In order to remove any predosed PVP from the electrode surface after platinum deposition (and so as not to disturb the single crystalline nature of the metal surface), the method first reported by Koperet al. ${ }^{21}$ (based on exposure of the electrode to piranha solution) was employed.

Surface Analysis Using XPS. XPS measurements were performed on a Kratos Axis Ultra-DLD photoelectron spectrometer, using monochromatic $\mathrm{Al}$ radiation operating at $120 \mathrm{~W}$. The base pressure during acquisition was $1 \times 10^{-9}$ Torr. Spectra were collected in the hybrid operating mode over an approximate area of $400 \times 300 \mu \mathrm{m}$, at pass energies of 40 

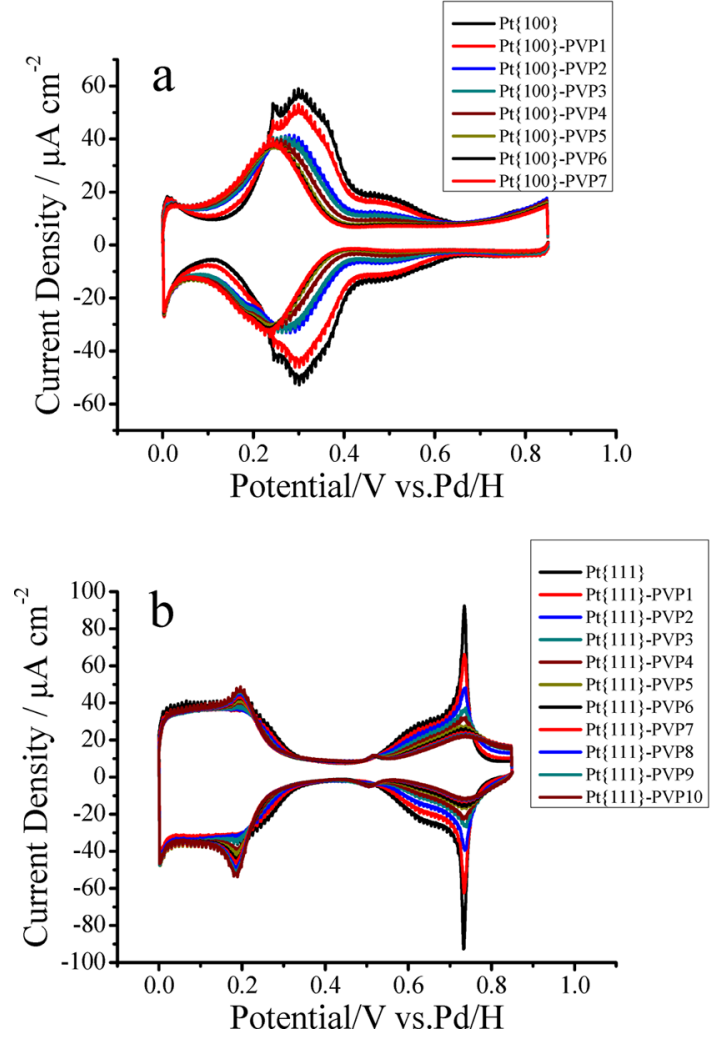
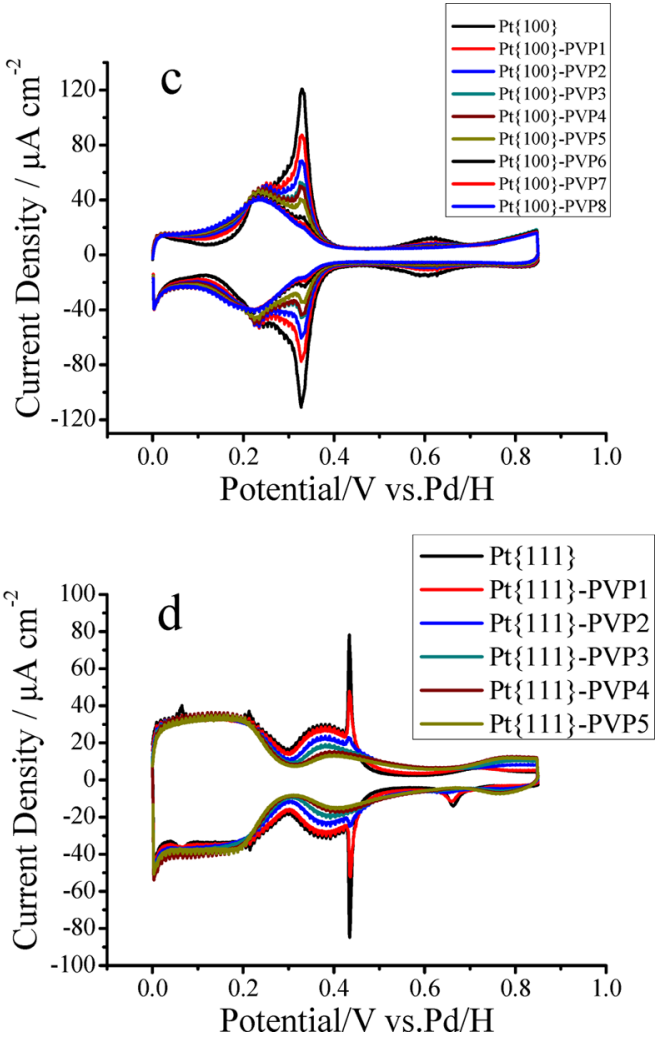

Figure 1. (a-d). Increasing PVP coverage on $\operatorname{Pt}\{100\}$ and $\operatorname{Pt}\{111\}: \operatorname{Pt}\{100\}$ in (a) perchloric acid and (c) sulfuric acid; $\operatorname{Pt}\{111\}$ in (b) perchloric acid and (d) sulfuric acid. Scan rate $50 \mathrm{mV} \mathrm{s}^{-1}$. Perchloric acid concentration: $0.1 \mathrm{~mol} \mathrm{dm}^{-3}$. Sulfuric acid concentration: $0.1 \mathrm{~mol} \mathrm{dm}^{-3}$.

and $160 \mathrm{eV}$ for high resolution and survey scans, respectively. The spectra were subsequently analyzed through CasaXPS v.2.3.15 using sensitivity factors supplied by the manufacturer. Transfer of all PVP - dosed samples from the electrochemical cell to UHV was facilitated by a rapid pump down auxiliary chamber attached to the XPS spectrometer and a custom built crystal holder adapted to hold several Clavilier bead electrodes simultaneously.

Density Functional Calculations. The calculations presented here utilize density functional theory as implemented in the code VASP (Vienna Ab-initio Simulation Package). ${ }^{22,23}$ The exchange and correlation energies are described by the generalized gradient approximation with the PBE functional. ${ }^{24}$ Projector augmented-wave (PAW) pseudopotentials ${ }^{25,26}$ were used to represent the core states of the atoms. A plane wave basis set with a cutoff energy of $400 \mathrm{eV}$ was used throughout.

A sampling grid of $5 \times 5 \times 5 k$-points in reciprocal space was necessary to converge the energy of the fcc bulk metal unit cell. The $k$-points were obtained using the Monkhorst-Pack scheme with convergence of the total energy with respect to $k$-point sampling accelerated using second-order Methfessel-Paxton smearing with a width of $0.1 \mathrm{eV}$. A bulk calculated equilibrium lattice constant of $3.986 \AA$ was obtained, in good agreement with the experimental value of $3.924 \AA$.

For the simulation of surfaces, a vacuum gap of $10 \AA$ perpendicular to the surface plane was introduced to ensure that interactions between slab images are negligible. In order to minimize lateral interactions between periodic images, a $p(4 \times$ 4) slab was necessary due to the relatively large size of the adsorbate used in these calculations. In all surface calculations, cell vectors were kept fixed to preserve the periodicity of the bulk termination. In calculating the optimized surface structures, a five-layer slab of metal atoms, with the lower two layers frozen at the bulk positions, was employed. The metal slab supercell is square with dimensions $a=b=11.9589$ $\AA$, $c=17.9726 \AA$ (including vacuum gap) containing $90 \mathrm{Pt}$ atoms. A 3-layer slab was utilized for calculating the vibrational modes with the same dimensions in vectors $a$ and $b$ containing $54 \mathrm{Pt}$ atoms. The surface calculations use a $3 \times 3 \times 1 k$-point scheme since the $a$ and $b$ dimensions are greater than the bulk and only $1 k$-point is required perpendicular to the slab surface. The calculated structures where also reoptimized using the D3 correction of Grimme $^{27}$ in order to assess the effect of dispersion interactions on the $\mathrm{PVP}-$ surface interaction.

To obtain the structure of adsorbed molecules, all metal atoms not previously described as frozen, and all adsorbate atoms, were optimized. A relaxation of the clean surface was found to result in a reduction of the interlayer spacing to 1.943 $\AA$, a decrease of $-15.6 \%$, and this relaxed clean surface was used as the reference for calculations of adsorption energies.

\section{RESULTS AND DISCUSSION}

Analysis of the Irreversible Adsorption of PVP using Cyclic Voltammetry. Figure 1 shows cyclic voltammetry (CV) data for irreversibly adsorbed PVP using Pt $\{111\}$ and $\operatorname{Pt}\{100\}$ electrodes. Two electrolytes were utilized in these experiments. Using aqueous sulfuric acid allowed the specific adsorption of sulfate anions on platinum ${ }^{28}$ to be monitored as a function of PVP loading. This affords information concerning both the competitive adsorption of sulfate with PVP and qualitative information regarding the long-range order of the electrosorbed sulfate surface adlayer. ${ }^{29}$ In contrast, utilizing aqueous perchloric acid electrolyte enables one to assess how PVP influences $\mathrm{OH}$ adsorption which is strongly surface 
structure sensitive on platinum. ${ }^{30}$ In both electrolytes, the socalled hydrogen underpotential (HUPD) region between 0 and $0.3 \mathrm{~V}$ is often used as both a proxy for surface coverages and for changes in the lateral interactions that might be occurring within the electrosorbed HUPD adlayer itself. ${ }^{3}$ Attenuation of HUPD charge (peak area) as a function of adsorbate coverage is almost universally regarded as being due to competitive adsorption of the chemisorbate which blocks HUPD sites. ${ }^{31,32}$ Together with the clean surface voltammetric response, increasing amounts of PVP adsorbed are denoted by the nomenclature "PVP $n$ " in the figure with the highest value of $n$ denoting the highest PVP coverage. Upon each addition of PVP, it took only a few potential cycles for the CVs to stabilize, after which no further change occurred even after leaving the surface at open circuit potential for a few hours.

It will be seen from Figure 1, parts a and c, that, for Pt $\{100\}$ in both perchloric and sulfuric acid, as $n$ increases the HUPD charge between $0-0.4 \mathrm{~V}$ tends to decrease until a constant limiting value of approximately $50 \%$ of the clean surface value is reached. We interpret this residual HUPD charge as arising from Pt sites not blocked by bonding with PVP. Presumably, steric interactions preclude a complete binding of all PVP monomer units within the polymer with these vacant surface $\mathrm{Pt}$ sites, irrespective of the PVP exposure time used to form the irreversibly adsorbed polymer layer. For perchloric acid, $\mathrm{OH}$ adsorption on $\operatorname{Pt}\{100\}(0.4-0.6 \mathrm{~V})^{33}$ is also attenuated markedly by increasing PVP loadings. This phenomenon is also seen for $\mathrm{Pt}\{111\}$ in perchloric acid electrolyte whereby the $\mathrm{OH}$ adsorption associated with the so-called "butterfly" feature $^{34}$ between 0.6 and $0.8 \mathrm{~V}$ is quenched to approximately $30 \%$ of its original clean surface value. This is also true of the analogous sulfate anion peak between 0.3 and $0.6 \mathrm{~V}$ for $\operatorname{Pt}\{111\}$ in sulfuric acid. Interestingly, suppression of sulfate anion adsorption by PVP is reflected by a corresponding increase in charge density associated with $\mathrm{OH}$ adsorption between 0.6 and $0.8 \mathrm{~V}$ (Figure 2). Normally this $\mathrm{OH}$ feature is not observed in

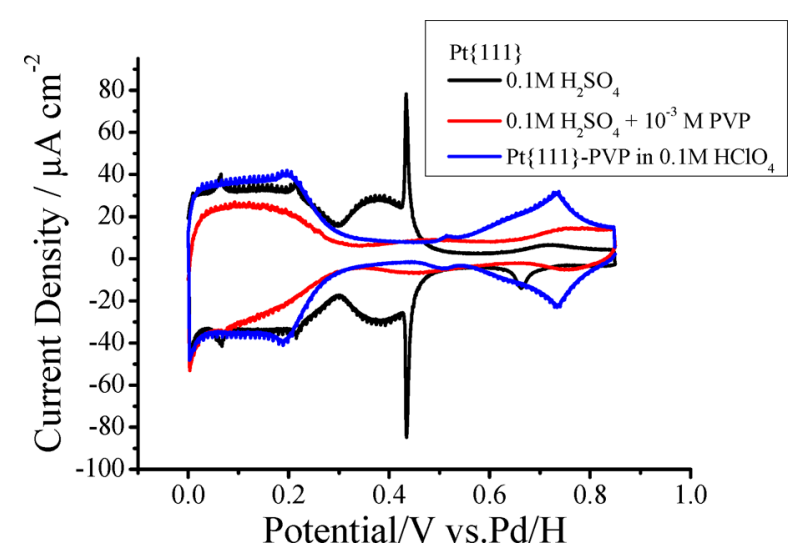

Figure 2. Black curve corresponds to $\operatorname{Pt}\{111\}$ in $0.1 \mathrm{M}$ sulfuric acid, blue curve to CV PVP5 in Figure 1c and the red curve to PVP adsorbed on $\operatorname{Pt}\{111\}$ in $0.1 \mathrm{M}$ sulfuric acid containing $10^{-3} \mathrm{M}$ PVP. Scan rate: $50 \mathrm{mV} \mathrm{s}^{-1}$.

sulfuric acid containing electrolytes at concentrations $>10^{-5}$ $\mathrm{M}^{35}$ due to competitive adsorption of sulfate with water dissociation and $\mathrm{OH}$ formation. Hence, although areas of $\operatorname{Pt}\{111\}$ free of PVP clearly coexist with the polymer layer, these areas appear not to favor sulfate electrosorption. We suggest that the long-range $\{111\}$ order necessary to facilitate the formation of the sulfate adlayer ${ }^{36}$ is no longer available due to the smaller domains of $\mathrm{Pt}\{111\}$ present on the PVPmodified surface. It is noted that the total HUPD charge between 0 and $0.3 \mathrm{~V}$ in both electrolytes remains almost constant as a function of increasing amounts of PVP although some new interactions are indicated by the presence of a peak $0.19 \mathrm{~V}$ in perchloric acid. Hence, a clear delineation between the behavior of adsorbed anions $(\mathrm{OH}$, sulfate) and electrosorbed hydrogen is observed whereby adsorbed PVP is insufficiently capable of blocking HUPD processes but readily blocks anion adsorption. Moreover, we shall see later that there is very little difference in the overall coverage of PVP on both $\mathrm{Pt}\{111\}$ and Pt $\{100\}$ using XPS and therefore, such differences must reflect differences in the competitive adsorption of PVP and HUPD on Pt $\{\mathrm{hkl}\}$. That is, PVP is more strongly bound to $\operatorname{Pt}\{100\}$ than it is to $\operatorname{Pt}\{111\}$.

Figure 2 also shows how irreversible adsorption of PVP on $\mathrm{Pt}\{111\}$ (PVP5 in $0.1 \mathrm{M}$ perchloric acid as Figure 1b) compares with more "forcing" conditions whereby PVP is actually dissolved in the sulfuric acid electrolyte (as first reported in ref 14).

Two points are apparent from Figure 2. The first is that, as mentioned earlier, an $\mathrm{OH}$ peak emerges from the $\mathrm{CV}$ even in sulfuric acid. It overlaps with the more usual $\mathrm{Pt}\{111\} \mathrm{OH}$ peak potential between 0.7 and $0.8 \mathrm{~V}$ (see CV PVP5). Second, as the coverage of PVP is increased from that achieved via irreversible adsorption, a marked attenuation in the amount of HUPD charge is also observed together with further attenuation in the anion charge (broad feature between 0.3 and $0.6 \mathrm{~V}$ ). If one recalls that the quenching of HUPD states could not be achieved via irreversible adsorption, this finding has significance in relation to the nanoparticle shape directing agency of PVP. This is because it shows that under sufficiently forcing conditions, behavior more similar to PVP on $\operatorname{Pt}\{100\}$ is observed in that both anion and HUPD electrosorption processes may be blocked by PVP, i.e., a diminution in the divergence of response of $\{100\}$ and $\{111\}$ planes to PVP uptake seen at relatively large coverages. We have provided a complete analysis of the blocking of surface charge associated with PVP-modified $\mathrm{Pt}\{111\}$ in Figure 2 (in terms of attenuation of HUPD and anion charge) in the Supporting Information, Figure S1. It is evident from Figure S1 that the HUPD peak of $\mathrm{Pt}\{111\}$ is reduced by about $19 \%$ when PVP is adsorbed directly from the electrolyte whereas the terrace anion peak is reduced in size by well over $50 \%$.

In fact, Figure 3 demonstrates that contrary to expectations, the oxygen reduction reaction (ORR) $)^{37}$ on $\mathrm{Pt}\{111\}$ is enhanced in aqueous sulfuric acid electrolytes as a consequence of PVP adsorption even though, ostensibly, Pt sites are being blocked. This phenomenon is interpreted again in terms of breakup of the well-ordered sulfate adlayer on $\operatorname{Pt}\{111\}^{38}$ which acts normally to block oxygen adsorption. ${ }^{28}$ In spite of these clear indications of PVP blocking Pt surface sites (see Figure $3 b)$, astonishingly, little perturbation of HUPD sites on $\operatorname{Pt}\{111\}$ either in perchloric acid or sulfuric acid is observed in Figure 1. In contrast, Figure 4 shows the influence of PVP on the ORR on $\mathrm{Pt}\{100\}$ in $0.1 \mathrm{M}$ aqueous sulfuric acid. Behavior here is much more in accordance with expectations with a gradual increase in the overpotential for ORR as PVP coverage increases (PVP deactivates the surface toward ORR).

In order to test this hypothesis further, $\mathrm{CO}$ chemisorption was used as a chemical probe of the site-blocking abilities of $\mathrm{PVP}$ on $\mathrm{Pt}\{111\}$ and $\mathrm{Pt}\{100\}$. If PVP was acting as a very weakly adsorbed species on $\operatorname{Pt}\{111\}$ but exhibited a stronger, 

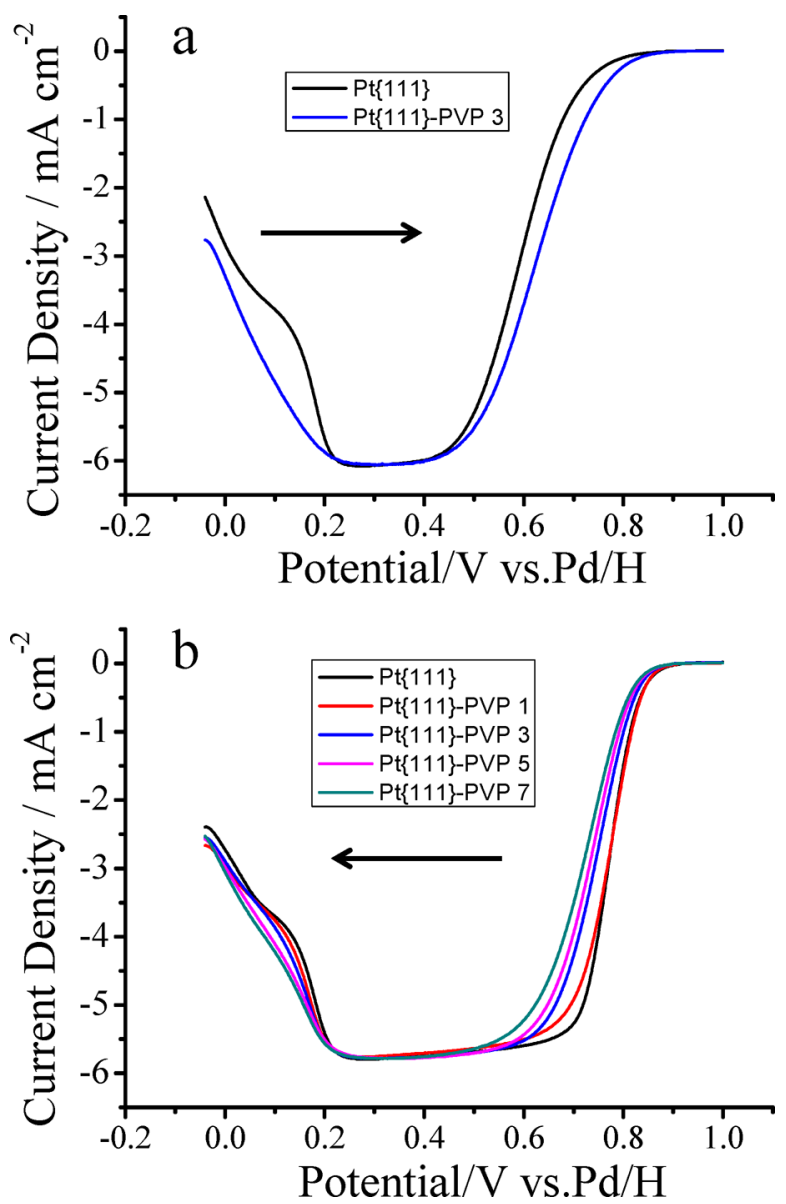

Figure 3. Effect of increasing PVP coverage on $\mathrm{Pt}\{111\}$ undergoing the ORR in oxygen-saturated (a) sulfuric acid and (b) perchloric acid. Scan rate: $30 \mathrm{mV} \mathrm{s}^{-1}$. Rotation speed $=1600 \mathrm{rpm}$. The arrows show the direction of change of the ORR wave (positive-going potential sweep) as a function of increasing PVP coverage.

chemisorption interaction on $\operatorname{Pt}\{100\}$, this may be reflected in the amount of $\mathrm{CO}$ that the PVP-modified Pt surfaces adsorb.

In Figure 5 is shown the result of dosing PVP on $\operatorname{Pt}\{111\}$ and $\mathrm{Pt}\{100\}$ and its effect on the amount of $\mathrm{CO}$ chemisorbed as measured using electrochemical stripping voltammetry. For both $\mathrm{Pt}\{111\}$ and $\mathrm{Pt}\{100\}$, PVP causes a shift to more negative potentials in the $\mathrm{CO}$ stripping peak potential compared to the clean surface response. This is consistent with smaller $\mathrm{CO}$ islands containing more defect sites capable of adsorbing $\mathrm{OH}$ at more negative potentials as PVP coverage increases. ${ }^{39}$ It is also in accordance with previous assertions concerning the decrease in size of the anion adlayers associated with $\operatorname{Pt}\{111\}$ voltammetry. More interestingly, in Table 1 , the change in the total stripping charge (amount) of adsorbed $\mathrm{CO}$ together with charge associated with HUPD and anion adsorption is compared for both $\mathrm{Pt}\{111\}$ and $\mathrm{Pt}\{100\}$ as a function of PVP loading.

Table 1 shows that, for $\operatorname{Pt}\{100\}$, the decrease in charge $Q$ (available from clean surface sites) mimics the decrease in $\mathrm{CO}$ uptake as PVP coverage increases. Hence, it is concluded that chemisorption of PVP blocks surface sites capable of adsorbing CO. In contrast, hardly any decrease in either HUPD or CO charge is registered for $\mathrm{Pt}\{111\}$ in spite of several PVP exposures (only sulfate anion adsorption charge decreases, HUPD charge remains unchanged). In this case, we speculate
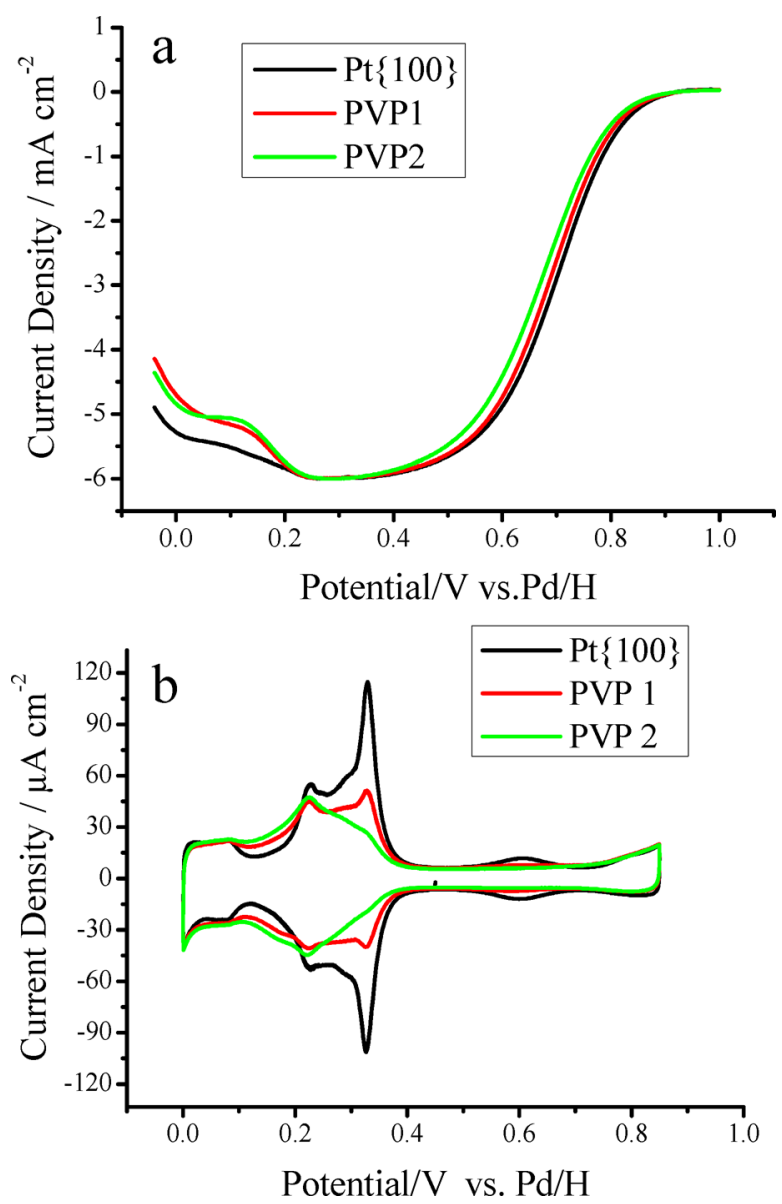

Figure 4. Effect of increasing PVP coverage on $\operatorname{Pt}\{100\}$ undergoing the ORR in oxygen saturated (a) sulfuric acid and (b) in oxygen-free electrolyte $\left(50 \mathrm{mV} \mathrm{s}^{-1}\right)$. Scan rate for ORR is $30 \mathrm{mV} \mathrm{s}^{-1}$. Rotation speed $=1600 \mathrm{rpm}$.

that the interaction of PVP with $\operatorname{Pt}\{111\}$ is not competitive with either HUPD processes or CO chemisorption. The conclusion drawn therefore, is that the PVP-Pt $\{111\}$ interaction is weaker than that of $\mathrm{PVP}-\mathrm{Pt}\{100\}$. That similar quantities of PVP are adsorbed on the surface nonetheless may be gleaned from our subsequent ex situ XPS measurements.

Since the shape-controlled growth of $\mathrm{Pt}$ nanoparticles using PVP not only involves terrace sites exclusively but must also involve interaction with step sites, a stepped $\mathrm{Pt}\{755\}$ electrode was also investigated in relation to PVP adsorption in $0.1 \mathrm{M}$ aqueous perchloric acid. Figure 6 shows the effect of increasing loadings of PVP on the clean surface voltammetry displayed by this surface. Pt $\{755\}$ may be written in microfacet nomenclature as $6\{111\} \times\{100\}$ so gives rise to both $\{111\}$ terrace sites and $\{111\} \times\{100\}$ step sites. In the clean $\mathrm{Pt}\{755\} \mathrm{CV}$ in Figure 6, these sites are discerned as being the relatively broad and relatively sharp peaks at 0.7 and $0.21 \mathrm{~V}$ respectively. It is noted that exposure to PVP causes a strong attenuation in the intensity of the step sites at $0.21 \mathrm{~V}$ together with the $\{111\} \mathrm{OH}$ terrace electrosorption peak centered at $0.7 \mathrm{~V}$.

However, the residual HUPD between 0 and $0.3 \mathrm{~V}$ corresponding to $\{111\}$ terraces remains almost unchanged after PVP deposition. Hence, the $\{111\}$ terrace features all behave as if they were independent of the step and closely reflect the behavior expected for a $\operatorname{Pt}\{111\}$ surface (see Figure 1b). However, the step feature much more resembles aspects of 
a

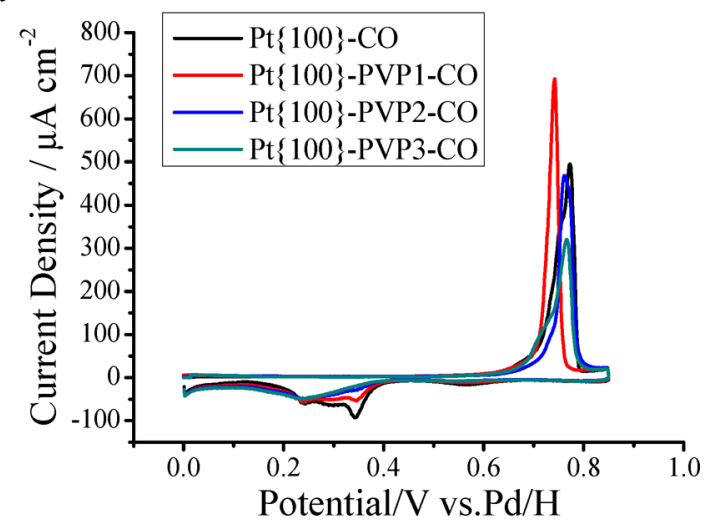

b

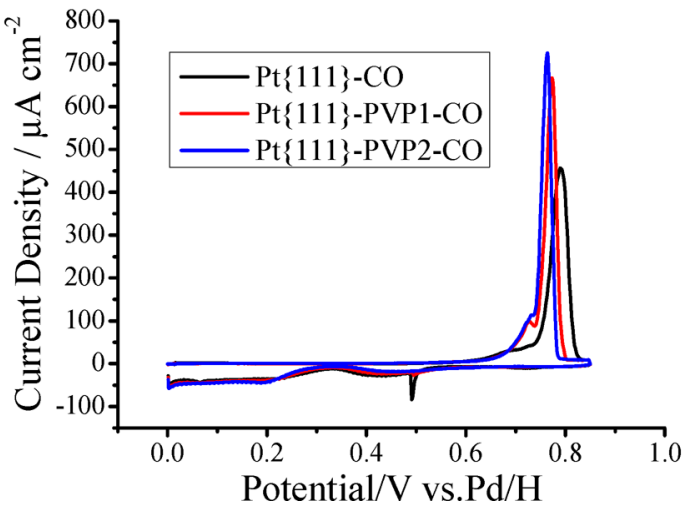

Figure 5. (a) $\mathrm{CO}$ electrooxidation on $\mathrm{Pt}\{100\}$ as a function of increasing PVPn loading. (b) CO electrooxidation on Pt $\{111\}$ as a function of increasing PVP $n$ loading. Start potential $=0.01 \mathrm{~V}$, sweep rate $=50 \mathrm{mV} \mathrm{s}^{-1}, 0.02 \mathrm{M}$ aqueous sulfuric acid electrolyte.

Table 1. Total Charges Associated with CO Stripping $\left(Q_{\mathrm{co}}\right)$ and Electrosorption Charge $Q$ on Clean Surfaces Integrated from 0 to $0.6 \mathrm{~V}(\operatorname{Pt}\{111\})$ and 0.1 to $0.45 \mathrm{~V}(\operatorname{Pt}\{100\})$ as a Function of Increasing PVP Coverage

\begin{tabular}{lcc} 
& $\mathrm{Q} / \mu \mathrm{C} \mathrm{cm}^{-2}$ & $\mathrm{Q}_{\mathrm{co}} / \mu \mathrm{C} \mathrm{cm}^{-2}$ \\
$\mathrm{Pt}\{111\}-\mathrm{CO}$ & $238 \pm 6$ & $421 \pm 11$ \\
$\mathrm{Pt}\{111\}-\mathrm{PVP} 1-\mathrm{CO}$ & $220 \pm 5$ & $438 \pm 15$ \\
$\operatorname{Pt}\{111\}-\mathrm{PVP} 2-\mathrm{CO}$ & $196 \pm 6$ & $431 \pm 14$ \\
$\operatorname{Pt}\{100\}-\mathrm{CO}$ & $175 \pm 9$ & $347 \pm 5$ \\
$\operatorname{Pt}\{100\}-\mathrm{PVP} 1-\mathrm{CO}$ & $155 \pm 8$ & $306 \pm 11$ \\
$\operatorname{Pt}\{100\}-\mathrm{PVP} 2-\mathrm{CO}$ & $138 \pm 4$ & $266 \pm 8$ \\
$\operatorname{Pt}\{100\}-\mathrm{PVP} 3-\mathrm{CO}$ & $131 \pm 6$ & $232 \pm 9$ \\
\hline
\end{tabular}

$\operatorname{Pt}\{100\}$ although complete attenuation of these step site peaks indicates a strong and complete blocking of surface step sites by PVP suggesting strong chemisorption of PVP is occurring selectively at step sites.

XPS Studies of Irreversibly Adsorbed PVP Adlayers. Figure 7 shows XPS scans of irreversibly adsorbed PVP adlayers on $\operatorname{Pt}\{111\}$ and $\operatorname{Pt}\{100\}$ electrodes. It is noted that in terms of relative intensities, all XPS peaks give rise to similar values indicating a similar overall coverage of PVP in both cases. The differences observed may be ascribed to some fortuitous carbonaceous (CO, graphitic carbon etc.) species that form during transfer to UHV. For $\mathrm{Pt}\{111\}$ (Figure 7a), based on a N surface atom concentration of $6 \%$, a theoretical carbon surface atom concentration of roughly $6 \times 6 \%=36 \%$ might be

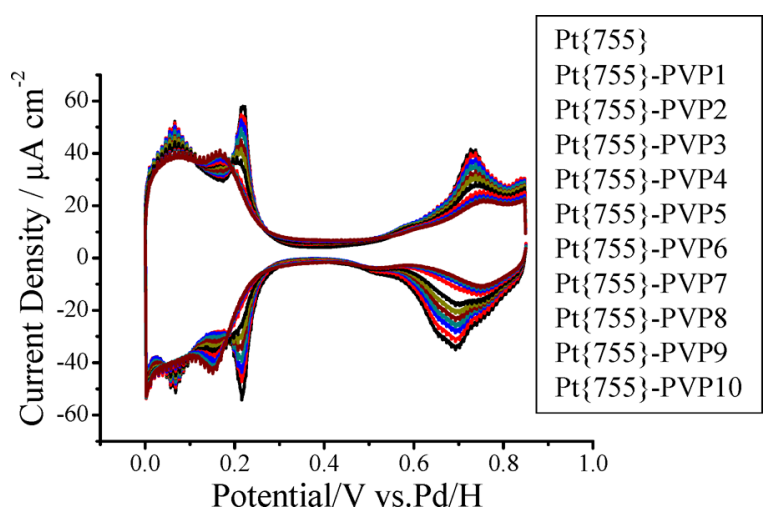

Figure 6. CVs of increasing amounts of PVP adsorbed on $\operatorname{Pt}\{755\}$ in $0.1 \mathrm{M}$ aqueous perchloric acid. Sweep rate $=50 \mathrm{mV} \mathrm{s}^{-1}$.
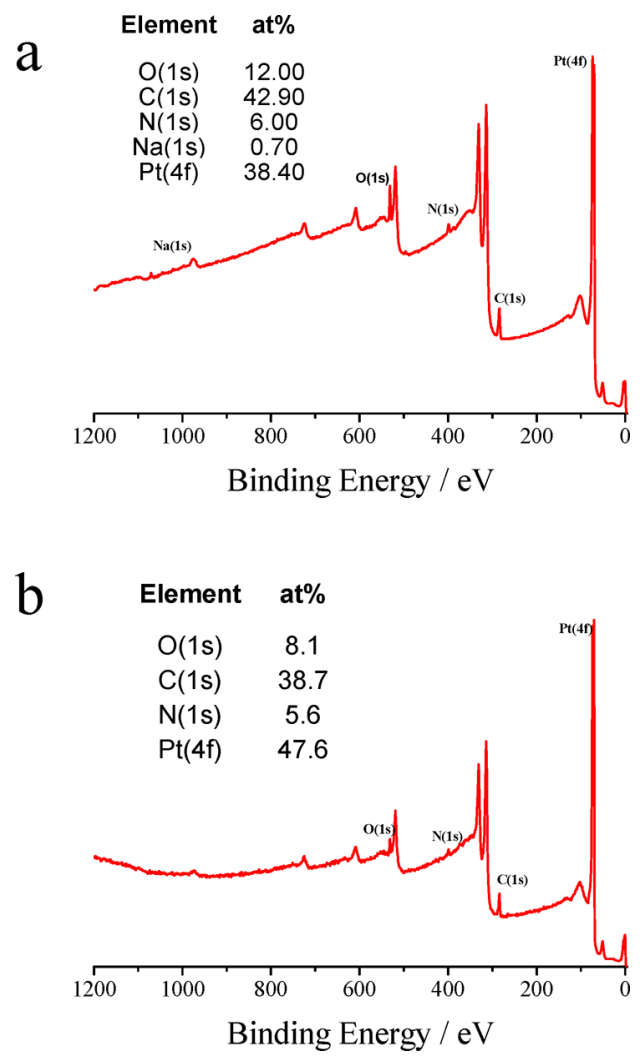

Figure 7. (a) Full range ex situ XPS scan of PVP irreversibly adsorbed on $\mathrm{Pt}\{111\}$. Surface concentrations of all surface atoms are listed. The CV collected prior to placing sample in XPS spectrometer resembled PVP7 in Figure 1d. (b) Full range ex situ XPS scan of PVP irreversibly adsorbed on $\mathrm{Pt}\{100\}$. Surface concentrations of all surface atoms are listed. The CV collected prior to transfer into the XPS spectrometer resembled PVP7 in Figure 1c.

expected. The actual value is $42 \%$ according to the Casa surface analysis which represents an "excess" of $42 \%-36 \%=6 \%$ of surface carbon over and above that expected from a pure PVP adlayer adsorbed on Pt. Reconciliation may be found if one notes that according to strictly stoichiometric considerations, the surface atomic concentrations of nitrogen and oxygen in PVP should be equal. Since the amount of surface oxygen determined from XPS is $12 \%, 6 \%$ "excess" oxygen is recorded. If this is matched with the excess carbon, the majority impurity in UHV is consistent with a surface concentration of $6 \%$ carbon monoxide which inevitably tends to adsorb from UHV onto Pt 
surface sites. However, smaller amounts of adsorbed CO combined with graphitic carbon and retained water or surface oxide might also give rise to such a result. For the $\operatorname{Pt}\{100\}$ spectra, stoichiometric analysis for PVP on Pt results in a much closer fit between theory and experiment. In fact the "excess" O in this case is just $2 \%$ based on the nitrogen concentration and perhaps 5\% for the "excess" carbon indicating far less adsorbed $\mathrm{CO}$ than for $\mathrm{Pt}\{111\}$ but perhaps a significant amount of graphitic carbon (3\%) as a proportion of total coverage. On the basis of the intensity of the $\mathrm{Pt} 4 \mathrm{f}$ peaks, the $\mathrm{Pt}\{111\}$ surface exhibits a slightly higher coverage of PVP than Pt $\{100\}$.

One may distinguish between both of these cases by fitting peaks to high resolution XPS data to extract binding energies of the various chemically distinct surface species. In Figure 8 , is shown high resolution XPS data corresponding to the $\mathrm{C}, \mathrm{N}$, and $\mathrm{O} 1 \mathrm{~s}$ regions of the data shown in Figure 7.

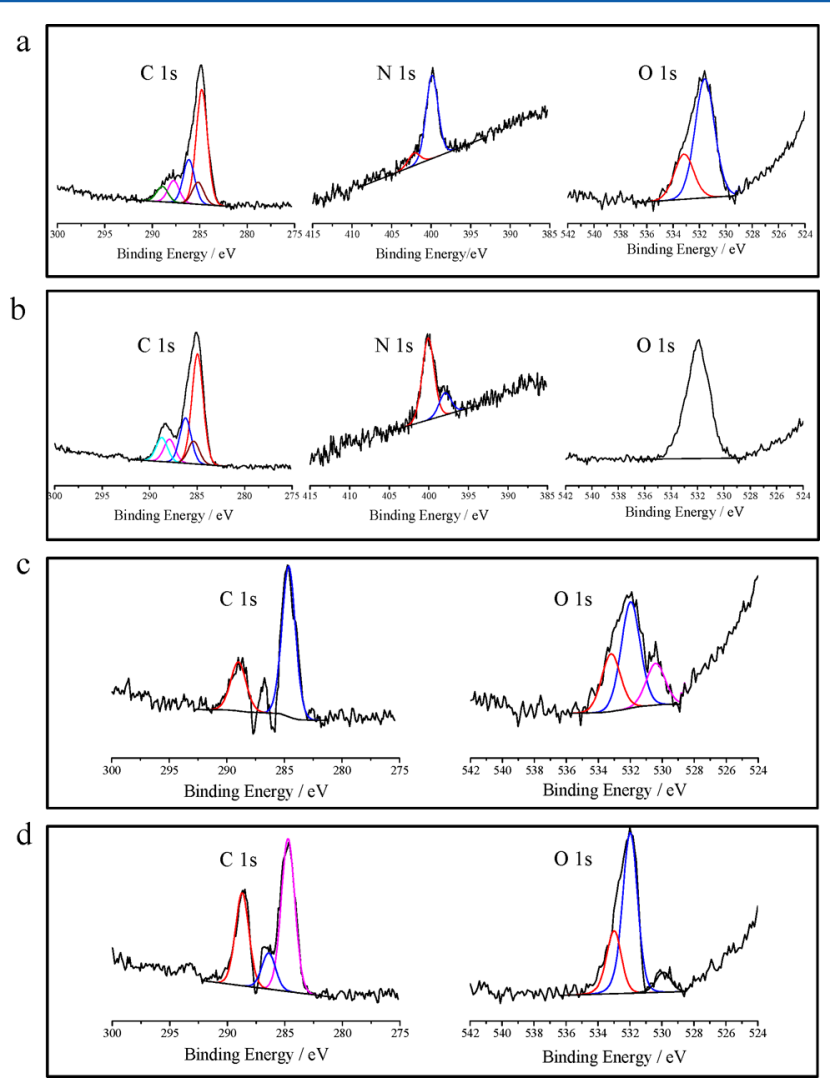

Figure 8. (a) High resolution ex situ XPS scan of C, N, and O 1s regions of PVP irreversibly adsorbed on $\mathrm{Pt}\{100\}$. (b) High resolution ex situ XPS scan of $\mathrm{C}, \mathrm{N}$, and $\mathrm{O} 1 \mathrm{~s}$ regions of PVP irreversibly adsorbed on $\mathrm{Pt}\{111\}$. (c) High resolution ex situ XPS scan of $\mathrm{C}$ and $\mathrm{O}$ 1 s regions of PVP irreversibly adsorbed on Pt $\{100\}$ but with bulk PVP features subtracted. (d) High resolution ex situ XPS scan of C and O 1 s regions of PVP irreversibly adsorbed on $\mathrm{Pt}\{111\}$ but with bulk PVP features subtracted.

The $\mathrm{N}$ 1s region of PVP adsorbed on both surfaces gives rise to a large peak at a binding energy of $399.9 \mathrm{eV}$ corresponding to the value found for bulk PVP. ${ }^{7}$ This indicates that the majority of $\mathrm{N}$ atoms associated with PVP remain largely unperturbed by the Pt surface suggesting that these atoms are not involved in surface bonding. There are minor components observed at $402 \mathrm{eV}$ corresponding to protonated nitrogen ${ }^{9}$ and $398 \mathrm{eV}$ associated with metal-N binding. ${ }^{6}$ Over 15 different UHV transfers and XPS sample measurements were under- taken to check for reproducibility in the data. The two minor components of the nitrogen XPS were found to be irreproducible. When incomplete removal of the sulfuric acid electrolyte during the water washing step occurred, the $402 \mathrm{eV}$ peak would be large and accompanied by a strong XPS signal for sulfate anions (not shown), signifying protonation of the nitrogen by sulfuric acid. In the case of the $398 \mathrm{eV}$ component, this was randomly observed on both $\operatorname{Pt}\{111\}$ and $\operatorname{Pt}\{100\}$ samples and therefore, we ascribe this feature to possible impurities in the PVP and/or acid hydrolysis of the polymer or to $\mathrm{X}$-ray beam damage.

The C 1s region of adsorbed PVP is somewhat complex but peak fitting always led to a simple superposition of "unperturbed" PVP and PVP C 1s signal modified by interaction with the $\mathrm{Pt}$ surface. This may superficially be recognized by the high binding energy $\mathrm{C} 1 \mathrm{~s}$ peak centered at $288 \mathrm{eV}$. Clearly, this corresponds to electron emission from the carbon atom of the carbonyl substituent of the amide group. However, peak deconvolution of this feature always produced two components, one at approximately $287.9 \mathrm{eV}$ ascribable to bulk PVP and another approximately $1 \mathrm{eV}$ greater in binding energy. We interpret the latter as being due to carbonyl bonding to the $\mathrm{Pt}$ surface directly. This interpretation is consistent with both the CV results in which only partial blocking of HUPD sites by PVP was observed and previous XPS results showing charge transfer away from PVP to Pt thus increasing the binding energy of the oxygen 1s peak. We suggest that charge is also transferred from the carbon atoms of the carbonyl in this process and therefore, more specifically, charge transfer from the carbonyl group as a whole to platinum fits the data more extensively. In order to highlight this point, subtraction of the C 1s components of bulk PVP, scaled to match the intensity of the $288 \mathrm{eV}$ peak, are shown in Figures 8, part $\mathrm{c}$ and $\mathrm{d}$. It is apparent that upon doing this, only two clear components remain that may not be ascribed to bulk PVP. These occur at a binding energy around 288.6-288.9 and at 284.6-284.8 eV. The later are clearly due to residual graphitic carbon collected during sample transfer, which also contributes to the excess carbon noted from the long-range XPS scans in Figure 7. The former is the $\mathrm{C} 1 \mathrm{~s}$ binding energy component due to PVP bonded directly to Pt. The proportion of surface bound PVP carbonyl lies between 30 and 50\% of total PVP amount suggesting every second or third PVP carbonyl group is bonded directly to Pt.

A similar analysis was carried out for the oxygen 1s peaks. Both $\operatorname{Pt}\{111\}$ and $\operatorname{Pt}\{100\}$ give rise to three distinct components after subtraction of the bulk PVP peaks centered around 530, 532, and $533 \mathrm{eV}$. The first of these may readily be ascribed to oxygen adatoms picked up during transfer to $\mathrm{UHV}^{40}$ The third, is in the region expected for carboxylate oxygen. However, based on the fact that no $\mathrm{C} 1 \mathrm{~s}$ binding energy signal for carboxylate could be observed, we ascribe this third peak to oxygen atoms in water that is still bound to the Pt-PVP interface. ${ }^{41}$ The $532 \mathrm{eV}$ peak is consistent with previous measurements showing a shift to higher binding energy of the O 1s peak of PVP when bonded to platinum., Hence, XPS reveals very little difference between $\operatorname{Pt}\{111\}$ and Pt $\{100\}$ toward PVP. Both surfaces indicate that the carbonyl of PVP is bound to Pt with transfer of electron charge toward the metal. Only a fraction of the total number of carbonyl substituents are bound to $\mathrm{Pt}$ and differences that may be observed between $\operatorname{Pt}\{111\}$ and $\operatorname{Pt}\{100\}$ may readily be 
explained in terms of the coadsorption of fortuitous impurities such as graphitic carbon, oxide, water and CO.

PVP-Controlled Pt Nucleation and Growth in Two Dimensions. In order to investigate the surface morphology of homoepitaxial Pt deposits with and without the influence of irreversibly adsorbed PVP, forced deposition of platinum was investigated. Here, we wish to restrict nucleation and growth within a two-dimensional space so as to gain insights concerning the bulk three-dimensional system normally used to grow colloidal particles. If all of the Pt complex ions contained in the chloroplatinic acid droplet attached to the electrode were reduced in this step, an upper limit on the amount of Pt deposited would be approximately 1 monolayer depending on the precise volume of the droplet attached. Figure 9 shows the result of depositing one ( $a$ and $c$ ) and two
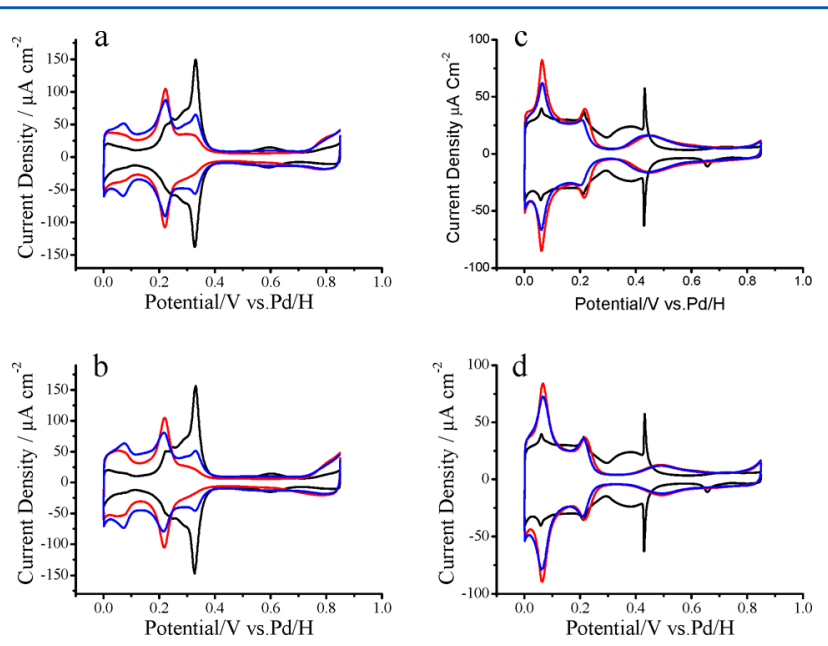

Figure 9. Pt forced deposition on $\mathrm{Pt}\{100\}$ : (a) one droplet deposited, (b) two droplets deposited and $\operatorname{Pt}\{111\}$ (c) one droplet deposited, (d) two droplets deposited. $0.1 \mathrm{M} \mathrm{H}_{2} \mathrm{SO}_{4}$. Sweep rate $=50 \mathrm{mV} \mathrm{s}^{-1}$. Black line, clean surface $\mathrm{CV}$; red line, $\mathrm{CV}$ after Pt deposition; blue line, after Pt deposition on PVP modified surface and with PVP adlayer subsequently removed.

sequential (b and d) droplets of chloroplatinic acid under an atmosphere of hydrogen. In the case of homoepitaxy on $\operatorname{Pt}\{111\}$, irrespective of the presence or absence of PVP, an identical surface morphology results with short $\{111\}$ terraces (0.45 V broad peak), mainly $\{111\} \times\{111\}$ steps $(0.05 \mathrm{~V}$ peak) and very small intensity $\{100\} \times\{111\}$ steps (peak at $0.22 \mathrm{~V}$ ). Even increasing the amount of Pt deposited has no impact on this trend although the resulting film exhibits even shorter $\{111\}$ terraces as signified by the reduced intensity and shift to more positive potentials of the $0.45 \mathrm{~V}$ peak. In contrast, the amount of long-range two dimensionally ordered $\{100\}$ terraces (as signified by the shape and intensity of the electrosorption peak at $0.32 \mathrm{~V}$ ) is always larger when PVP is present than when it is not. This remarkable difference in behavior attests to the strong structure-directing agency of PVP during nucleation and growth in two and three dimensions. In contrast to $\operatorname{Pt}\{111\}$, significant $\{100\} \times\{111\}$ step features in the deposit are noted at $0.21 \mathrm{~V}$.

Theoretical Calculations of PVP Adsorption on Pt. To carry out periodic DFT calculations of the adsorption mode for PVP at the $\{111\}$ and $\{100\}$ Pt surfaces we use a single PVP monomer unit with a propyl chain at $\mathrm{N}$ to represent the polymer backbone. Figure 10 shows the optimized structures for adsorption through the amide carbonyl group in an atop a

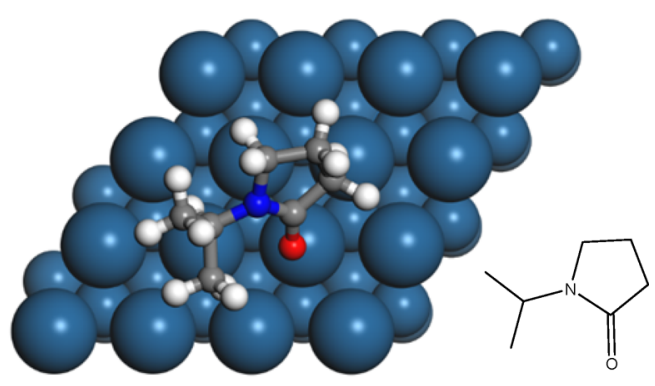

b

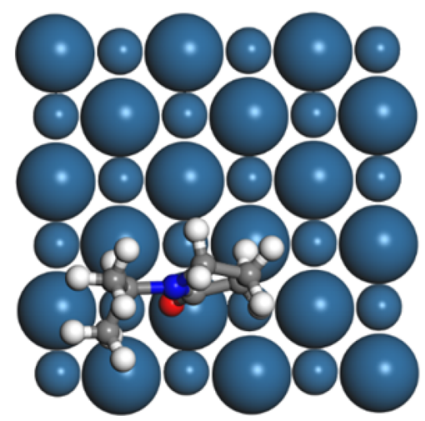

Figure 10. Calculated adsorption geometries for a single PVP monomer unit on (a) $\operatorname{Pt}\{111\}$ and (b) $\operatorname{Pt}\{100\}$ surfaces. The chemical structure of the $\mathrm{PVP}-$ monomer unit is given in part a. Atom colors follow: Pt, dark blue; C, gray; N, blue; O, red; $\mathrm{H}$, white. In part $\mathrm{b}$, the second layer Pt atoms are drawn with smaller radii for clarity.

fashion along with the chemical structure of this monomer unit. Tests for alternative modes of adsorption, such as through $\mathrm{N}$ or bridging $\mu_{2}(\mathrm{C}, \mathrm{O})$ parallel to the surface, did not result in favorable adsorption energies due to the steric limitations of the propyl group. The calculated adsorption energies for the structures shown in Figure 10 are -94 and $-55 \mathrm{~kJ} \mathrm{~mol}^{-1}$ for the $\{100\}$ and $\{111\}$ surfaces respectively and -142 and -125 $\mathrm{kJ} \mathrm{mol}{ }^{-1}$ when D3 corrections are applied. We note that the dispersion contribution to these adsorption energies gives up to $56 \%$ of the adsorption energy and so is a significant part of the interaction between the PVP monomer unit and the surfaces, particularly for the close packed $\{111\}$ case. For the equivalent Ag surfaces it has been found that calculated dispersion corrected adsorption energies using a more simplified model of the PVP monomer are roughly three times those found without inclusion of dispersion. ${ }^{42}$ The molecular configurations found in that case place the five membered ring of the PVP monomer roughly parallel to the $\mathrm{Ag}$ surface, presumably to maximize the dispersion interaction. Our results suggest that the chemical short-range interaction represented by the pure GGA-DFT functional influence the structure more in the case of $\mathrm{Pt}$ than Ag. We find that for PVP on Pt surfaces the $\eta^{1}(\mathrm{O})$ configuration is the most likely adsorption mode. In these structures the carbonyl oxygen is notably closer to the coordinated surface $\mathrm{Pt}$ atom on $\{100\}$ than on $\{111\}, 2.11$ cf. $2.21 \AA$.

This is in agreement with the HUPD data presented earlier suggesting a stronger adsorption of PVP to the $\{100\}$ surface compared to the $\{111\}$. For the isolated PVP monomer unit the calculated $\mathrm{C}=\mathrm{O}$ stretching mode would occur at 1714 $\mathrm{cm}^{-1}$, using the level of theory employed in this work. Calculation of the vibrational frequencies for the adsorbed molecules show a significant red shift with $\mathrm{C}=\mathrm{O}$ stretching modes at $1559 \mathrm{~cm}^{-1}$ for $\operatorname{Pt}\{111\}$ and $1588 \mathrm{~cm}^{-1}$ for $\operatorname{Pt}\{100\}$. This is a stronger effect than is observed experimentally for 
PVP adsorbed on Pt nanoparticles whereby a red shift upon adsorption from 1662 to $1606 \mathrm{~cm}^{-1}$ was reported in ref 3 . This may be due to the use of a clean surface in the calculations which neglects the destabilizing effects of other adsorbates.

Comparison of Pt Nanoparticle Growth with Present Findings. The growth of $\mathrm{Pt}$ nanoparticles in the presence of PVP has been studied extensively in the literature. ${ }^{4-45}$ In ref 42, it was found that the Pt nanoparticle shape depends strongly on both the initial PVP concentration and the rate of reduction of the $\mathrm{Pt}$ precursor complex. In most cases, tetrahedral or cuboctahedral shapes result, in contrast to predictions made in the present study and in refs 43 and 44 . However, when the ratio of PVP to Pt precursor complex was kept low, nanocubes resulted. ${ }^{43}$ In our study, we have found that irreversible adsorption of PVP onto $\mathrm{Pt}\{111\}$ behaves differently to $\mathrm{Pt}\{100\}$ and indeed to step sites, in that a weaker interaction (based on HUPD blocking, ORR activity, CO uptake, and DFT calculations) is found which predicts preferential growth of $\mathrm{Pt}$ nanocubes. However, we have also demonstrated that under more forcing conditions the surface interaction and coverage of PVP with $\mathrm{Pt}\{111\}$ increase leading to blocking of HUPD sites. This behavior would now be similar to that of $\operatorname{Pt}\{100\}$ whereby PVP at higher coverages competes successfully with HUPD processes for Pt sites. Hence, a prediction of SDA behavior in relation to PVP may be formulated. At relatively low ratios of PVP:Pt precursor, there is indeed a differentiation between how PVP bonds to $\{111\}$ terraces compared with $\{100\}$. However, at higher PVP:Pt complex precursor ratios, the difference between PVP interaction with $\{111\}$ and $\{100\}$ terraces diminishes such that tetrahedral or cuboctahedral shapes are favored. This prediction is consistent with all previous experimental studies of $\mathrm{Pt}$ nanoparticle formation using PVP as an SDA. To some extent, it is also in accordance with previous findings in relation to Pd nanoparticles whereby the bonding of PVP to palladium was critically dependent on the PVP:Pt complex precursor ratio used. $^{9}$

\section{CONCLUSIONS}

Well-defined electrode surfaces modified with controlled amounts of PVP have been investigated using voltammetry, ex situ XPS and DFT calculations. It is found that the adsorption of PVP is highly structure sensitive with strong adsorption exhibited by step and $\{100\}$ terrace sites with only very weak interactions observed between PVP and $\operatorname{Pt}\{111\}$ terraces, at least at relatively low loadings of PVP. Density functional theory calculations also confirmed that the monomer of PVP interacts more strongly with $\mathrm{Pt}\{100\}$ compared to $\operatorname{Pt}\{111\}$ sites $\left(-142\right.$ and $-125 \mathrm{~kJ} \mathrm{~mol}^{-1}$, respectively at the $\mathrm{PBE}+\mathrm{D} 3$ level). According to XPS, the main PVP-Pt interaction is associated with charge transfer from the carbonyl substituent of PVP toward the metal surface in accordance with earlier studies of PVP adsorbed on polycrystalline platinum surfaces. ${ }^{6,7}$ Irreversible adsorption of $\mathrm{Pt}$ adatoms onto $\mathrm{Pt}\{h k l\}$ surfaces with and without PVP-surface modification demonstrated a marked preference for $\{100\}$ facet formation on $\operatorname{Pt}\{100\}$ surfaces but no corresponding preferential $\{111\}$ facet growth on $\mathrm{Pt}\{111\}$ when PVP was present. Hence, the shape control exhibited by PVP in expediting the formation of cubic Pt nanoparticles is explicitly confirmed as arising from relatively weak PVP-Pt $\{111\}$ interactions. More usually, such deductions have been made post hoc by consideration of the actual outcome of an SDA process (when a nanoparticle has already formed) rather than at a fundamental, surface site level. However, the electrochemical approach used in the present study is well-suited to such problems since the structural sensitivity afforded by electrosorption readily reveals the sites being blocked by molecular species. Future work will be directed toward other SDA species, especially using single crystal surfaces as templates for nucleation and growth with and without the SDA adsorbed. In addition, the behavior of PVP adsorbed on other metal single crystal surfaces including palladium is presently being prepared. ${ }^{46}$

\section{ASSOCIATED CONTENT}

\section{Supporting Information}

The Supporting Information is available free of charge on the ACS Publications website at DOI: 10.1021/acs.jpcc.5b10910.

$\mathrm{CV}$ of $\mathrm{Pt}\{111\}$ before and after adsorption of PVP (PDF)

Excel spreadsheet used for recording the DFT energy calculations (XLSX)

Original data for all figures in the main text (ZIP)

Tar file for figures in the main text (ZIP)

\section{AUTHOR INFORMATION}

\section{Corresponding Authors}

*(G.A.A.) E-mail: Attard@cardiff.ac.uk.

*(S.-G.S.) E-mail: sgsun@xmu.edu.cn.

\section{Author Contributions}

The manuscript was written through contributions of all authors./All authors have given approval to the final version of the manuscript./These authors contributed equally.

Notes

The authors declare no competing financial interest.

\section{ACKNOWLEDGMENTS}

A.B. acknowledges the Ph.D. support from the EPSRC and J.Y.Y. acknowledges the fellowship support of the China Scholarship Council. This research was supported by NSFC grant $(21321002,21229301,21361140374)$ and EPSRC Grant $\mathrm{EP} / \mathrm{I038748/1}$. Via our membership of the U.K.'s HPC Materials Chemistry Consortium, which is funded by EPSRC (EP/L000202), this work made use of the facilities of HECToR and ARCHER. Computing resource was also provided by Advanced Research Computing at Cardiff (ARCCA) and the HPC-Wales supercomputer facilities.

\section{REFERENCES}

(1) Tang, Z.; Zhang, Q.; Yin, Y.; Chang, C.E. A. Facet Selectivity of Ligands on Silver Nanoplates: Molecular Mechanics Study. J. Phys. Chem. C 2014, 118, 21589-21598.

(2) Chen, D. H.; Ye, J. Y.; Xu, C. D.; Li, X.; Li, J. T.; Zhen, C. H.; Tian, N.; Zhou, Z. Y.; Sun, S. G. Interaction of Citrate with $\mathrm{Pt}(100)$ Surface Investigated by Cyclic Voltammetry Towards Understanding the Structure-Tuning Effect in Nanomaterials Synthesis. Sci. China: Chem. 2012, 55, 2353-2358.

(3) Attard, G. A.; Ye, J.-Y.; Jenkins, P.; Vidal-Iglesias, F. J.; Herrero, E.; Sun, S.-G. Citrate Adsorption on Pt $\{\mathrm{hkl}\}$ Electrodes and Its Role in the Formation of Shaped Pt Nanoparticles. J. Electroanal. Chem. 2013, $688,249-256$.

(4) Xu, C. D.; Ye, J. Y.; Chen, L.; Chen, D. H.; Li, J. T.; Zhen, C. H.; Sun, S. G. Cyclic Voltammetric Studies of Adsorption of Cetyltrimethylammonium Bromide and $\mathrm{HBr}$ on $\mathrm{Pt}(100)$ Towards Understanding Their Effects in Shape-Controlled Synthesis of Nanomaterials. Electrochim. Acta 2015, 162, 129-137. 
(5) Xia, Y. N.; Xiong, Y. J.; Lim, B.; Skrabalak, S. E. Shape-Controlled Synthesis of Metal Nanocrystals: Simple Chemistry Meets Complex Physics? Angew. Chem., Int. Ed. 2009, 48, 60-103.

(6) Borodko, Y.; Habas, S. E.; Koebel, M.; Yang, P. D.; Frei, H.; Somorjai, G. A. Probing the Interaction of Poly(Vinylpyrrolidone) with Platinum Nanocrystals by UV-Raman and FTIR. J. Phys. Chem. B 2006, 110, 23052-23059.

(7) Borodko, Y.; Humphrey, S. M.; Tilley, T. D.; Frei, H.; Somorjai, G. A. Charge-Transfer Interaction of Poly(Vinylpyrrolidone) with Platinum and Rhodium Nanoparticles. J. Phys. Chem. C 2007, 111, $6288-6295$.

(8) Qiu, L. M.; Liu, F.; Zhao, L. Z.; Yang, W. S.; Yao, J. N. Evidence of a Unique Electron Donor-Acceptor Property for Platinum Nanoparticles as Studied by XPS. Langmuir 2006, 22, 4480-4482.

(9) Xian, J.; Hua, Q.; Jiang, Z.; Ma, Y.; Huang, W. Size-Dependent Interaction of the Poly(N-Vinyl-2-Pyrrolidone) Capping Ligand with Pd Nanocrystals. Langmuir 2012, 28, 6736-41.

(10) Saidi, W. A.; Feng, H. J.; Fichthorn, K. A. Binding of Polyvinylpyrrolidone to Ag Surfaces: Insight into a Structure-Directing Agent from Dispersion-Corrected Density Functional Theory. J. Phys. Chem. C 2013, 117, 1163-1171.

(11) Zhou, Y.; Saidi, W. A.; Fichthorn, K. A. A Force Field for Describing the Polyvinylpyrrolidone-Mediated Solution-Phase Synthesis of Shape-Selective Ag Nanoparticles. J. Phys. Chem. C 2014, 118, 3366-3374.

(12) Levendorf, A. M.; Sun, S. G.; Tong, Y. Y. J. In Situ FTIR Investigation of Methanol and $\mathrm{CO}$ Electrooxidation on Cubic and Octahedral/Tetrahedral Pt Nanoparticles Having Residual PVP. Electrocatalysis 2014, 5, 248-255.

(13) Attard, G. A.; Bennett, J. A.; Mikheenko, I.; Jenkins, P.; Guan, S.; Macaskie, L. E.; Wood, J.; Wain, A. J. Semi-Hydrogenation of Alkynes at Single Crystal, Nanoparticle and Biogenic Nanoparticle Surfaces: The Role of Defects in Lindlar-Type Catalysts and the Origin of Their Selectivity. Faraday Discuss. 2013, 162, 57-75.

(14) Gasparotto, L. H. S.; Gomes, J. F.; Tremiliosi-Filho, G. CyclicVoltammetry Characteristics of Poly(Vinyl Pyrrolidone) (PVP) on Single-Crystal Pt Surfaces in Aqueous $\mathrm{H}_{2} \mathrm{SO}_{4}$. J. Electroanal. Chem. 2011, 663, 48-51.

(15) Xia, X. H.; Zeng, J.; Oetjen, L. K.; Li, Q. G.; Xia, Y. N. Quantitative Analysis of the Role Played by Poly(Vinylpyrrolidone) in Seed-Mediated Growth of Ag Nanocrystals. J. Am. Chem. Soc. 2012, 134, 1793-1801.

(16) Clavilier, J.; Faure, R.; Guinet, G.; Durand, R. Preparation of Mono-Crystalline $\mathrm{Pt}$ Microelectrodes and Electrochemical Study of the Plane Surfaces Cut in the Direction of the (111) and (110) Planes. J. Electroanal. Chem. Interfacial Electrochem. 1979, 107, 205-209.

(17) Kibler, L. A.; Cuesta, A.; Kleinert, M.; Kolb, D. M. In-Situ Stm Characterisation of the Surface Morphology of Platinum Single Crystal Electrodes as a Function of Their Preparation. J. Electroanal. Chem. 2000, 484, 73-82.

(18) Markovic, N.; Hanson, M.; Mcdougall, G.; Yeager, E. The Effects of Anions on Hydrogen Electrosorption on Platinum SingleCrystal Electrodes. J. Electroanal. Chem. Interfacial Electrochem. 1986, 214, 555-566.

(19) Cahan, B. D.; Villullas, H. M. The Hanging Meniscus RotatingDisk (HMRD). J. Electroanal. Chem. Interfacial Electrochem. 1991, 307, 263-268.

(20) Llorca, M. J.; Feliu, J. M.; Aldaz, A.; Clavilier, J. Formic-Acid Oxidation on Pd-Ad Plus Pt(100) and Pd-Ad Plus Pt(111) Electrodes. J. Electroanal. Chem. 1994, 376, 151-160.

(21) Monzo, J.; Koper, M. T.; Rodriguez, P. Removing Polyvinylpyrrolidone from Catalytic Pt Nanoparticles without Modification of Superficial Order. ChemPhysChem 2012, 13, 709-15.

(22) Kresse, G.; Furthmuller, J. Efficient Iterative Schemes for Ab Initio Total-Energy Calculations Using a Plane-Wave Basis Set. Phys. Rev. B: Condens. Matter Mater. Phys. 1996, 54, 11169-11186.

(23) Kresse, G.; Furthmuller, J. Efficiency of Ab-Initio Total Energy Calculations for Metals and Semiconductors Using a Plane-Wave Basis Set. Comput. Mater. Sci. 1996, 6, 15-50.
(24) Perdew, J. P.; Burke, K.; Ernzerhof, M. Generalized Gradient Approximation Made Simple. Phys. Rev. Lett. 1996, 77, 3865-3868.

(25) Blochl, P. E. Projector Augmented-Wave Method. Phys. Rev. B: Condens. Matter Mater. Phys. 1994, 50, 17953-17979.

(26) Kresse, G.; Joubert, D. From Ultrasoft Pseudopotentials to the Projector Augmented-Wave Method. Phys. Rev. B: Condens. Matter Mater. Phys. 1999, 59, 1758-1775.

(27) Grimme, S.; Antony, J.; Ehrlich, S.; Krieg, S. A consistent and accurate ab initio parametrization of density functional dispersion correction (dft-d) for the 94 elements H-Pu. J. Chem. Phys. 2010, 132, 154104.

(28) Lachenwitzer, A.; Li, N.; Lipkowski, J. Determination of the Acid Dissociation Constant for Bisulfate Adsorbed at the $\operatorname{Pt}(111)$ Electrode by Subtractively Normalized Interfacial Fourier Transform Infrared Spectroscopy. J. Electroanal. Chem. 2002, 532, 85-98.

(29) Hoshi, N.; Sakurada, A.; Nakamura, S.; Teruya, S.; Koga, O.; Hori, Y. Infrared Reflection Absorption Spectroscopy of Sulfuric Acid Anion Adsorbed on Stepped Surfaces of Platinum Single-Crystal Electrodes. J. Phys. Chem. B 2002, 106, 1985-1990.

(30) Gómez-Marín, A. M.; Feliu, J. M. Pt(111) Surface Disorder Kinetics in Perchloric Acid Solutions and the Influence of Specific Anion Adsorption. Electrochim. Acta 2012, 82, 558-569.

(31) Zolfaghari, A.; Villiard, F.; Chayer, M.; Jerkiewicz, G. Hydrogen Adsorption on $\mathrm{Pt}$ and $\mathrm{Rh}$ Electrodes and Blocking of Adsorption Sites by Chemisorbed Sulfur. J. Alloys Compd. 1997, 253-254, 481-487.

(32) Feliu, J. M.; Orts, J. M.; Femandez-Vega, A.; Aldaz, A.; Clavilier, J. Electrochemical Studies in Sulfuric-Acid-Solutions of Absorbed CO on Pt (111) Electrodes. J. Electroanal. Chem. Interfacial Electrochem. 1990, 296, 191-201.

(33) Gomez, R.; Orts, J. M.; Alvarez-Ruiz, B.; Feliu, J. M. Effect of Temperature on Hydrogen Adsorption on $\mathrm{Pt}(111), \mathrm{Pt}(110)$, and $\mathrm{Pt}(100)$ Electrodes in $0.1 \mathrm{M} \mathrm{HClO}_{4}$. J. Phys. Chem. B 2004, 108, 228238.

(34) Ahmed, M.; Morgan, D.; Attard, G. A.; Wright, E.; Thompsett, D.; Sharman, J. Unprecedented Structural Sensitivity toward Average Terrace Width: Nafion Adsorption at Pt $\{$ hkl $\}$ Electrodes. J. Phys. Chem. C 2011, 115, 17020-17027.

(35) Garcia-Araez, N.; Climent, V.; Rodriguez, P.; Feliu, J. M. Thermodynamic Analysis of (Bi)Sulphate Adsorption on a $\mathrm{Pt}(111)$ Electrode as a Function of pH. Electrochim. Acta 2008, 53, 6793-6806.

(36) Mostany, J.; Herrero, E.; Feliu, J. M.; Lipkowski, J. Thermodynamic Studies of Anion Adsorption at Stepped Platinum(hkl) Electrode Surfaces in Sulfuric Acid Solutions. J. Phys. Chem. B 2002, 106, 12787-12796.

(37) Wang, J. X.; Markovic, N. M.; Adzic, R. R. Kinetic Analysis of Oxygen Reduction on $\operatorname{Pt}(111)$ in Acid Solutions: Intrinsic Kinetic Parameters and Anion Adsorption Effects. J. Phys. Chem. B 2004, 108, 4127-4133.

(38) Funtikov, A. M.; Linke, U.; Stimming, U.; Vogel, R. An in-Situ STM Study of Anion Adsorption on $\mathrm{Pt}(111)$ from Sulfuric-AcidSolutions. Surf. Sci. 1995, 324, L343-L348.

(39) Farias, M. J. S.; Busó-Rogero, C.; Gisbert, R.; Herrero, E.; Feliu, J. M. Influence of the Co Adsorption Environment on Its Reactivity with (111) Terrace Sites in Stepped Pt Electrodes under Alkaline Media. J. Phys. Chem. C 2014, 118, 1925-1934.

(40) Peuckert, M.; Bonzel, H. P. Characterization of Oxidized Platinum Surfaces by X-Ray Photoelectron-Spectroscopy. Surf. Sci. 1984, 145, 239-259.

(41) Herman, G. S.; Dohnalek, Z.; Ruzycki, N.; Diebold, U. Experimental Investigation of the Interaction of Water and Methanol with Anatase-Tio2(101). J. Phys. Chem. B 2003, 107, 2788-2795.

(42) Al-Saidi, W. A.; Feng, H. J.; Fichthorn, K. A. Adsorption of Polyvinylpyrrolidone on $\mathrm{Ag}$ Surfaces: Insight into a StructureDirecting Agent. Nano Lett. 2012, 12, 997-1001.

(43) Teranishi, T.; Kurita, R.; Miyake, M. Shape Control of Pt Nanoparticles. J. Inorg. Organomet. Polym. 2000, 10, 145-156.

(44) Chen, J. Y.; Lim, B.; Lee, E. P.; Xia, Y. N. Shape-Controlled Synthesis of Platinum Nanocrystals for Catalytic and Electrocatalytic Applications. Nano Today 2009, 4, 81-95. 
(45) Peng, Z. M.; Yang, H. Designer Platinum Nanoparticles: Control of Shape, Composition in Alloy, Nanostructure and Electrocatalytic Property. Nano Today 2009, 4, 143-164.

(46) Attard, G. A.; Ye, J. Y.; S, S. G.; Brew, A.; Willock, D. J. Study the Adsorption of Polyvinylpyrrolidoneon Palladium Surfaces. Manuscript in preparation. 